\title{
5 Relationship between Body Mass Index and Blood Pressure among the Adult Population of Tawang Monpa, Arunachal Pradesh
}

\author{
Jyotismrita Phukan', *Dr. Tiluttoma Baruah², \\ ${ }^{1}$ Department of Anthropology, Research Scholar, Gauhati University, Guwahati, Assam, \\ India. \\ ${ }^{2}$ Department of Anthropology, Associate Professor, Cotton University, Guwahati, Assam, \\ India.email: tiluttoma.baruah@rediffmail.com
}

\section{Abstract}

The present study aims to determine the relationship between Body Mass Index(BMI) and Blood Pressure (Systolic Blood Pressure and Diastolic Blood Pressure) among the adult population of Monpas of Tawang, Arunachal Pradesh. Data on gender, height, weight, BMI and B.P were obtained by using a researcher data form. The data relating to the study were collected using standardised procedures. A total of 524 adult population participated in this study out of which 267 (50.95\%) were males and 257(49.05\%) were females with mean height, weight and BMI of $159.64 \mathrm{~cm}, 64.65 \mathrm{~kg}, 25.3 \mathrm{~kg} / \mathrm{m}^{2}$ respectively. The mean Systolic and Diastolic blood pressure were $126.57 \mathrm{mmHg}$ and $84.05 \mathrm{mmHg}$ respectively. The interrelationships between hypertension and obesity are two common and major health hazards. Hence the study was made to link up a relationship between these two parameters.

Keyword: Blood Pressure, Systolic Blood Pressure, Diastolic Blood Pressure, Body Mass Index, Hypertension, Obesity, Relationship

\section{Introduction}

Worldwide hypertension is found to be a major cause of premature heart disease, kidney disease and stroke. Blood pressure changes in relation to a person's activity and stress level. The risk of heart disease 


\section{(C) Jyotismrita Phukan, Dr. Tiluttoma Baruah}

and stroke has been found to be related directly to elevated blood pressure levels. No definite cause is responsible for the rise of blood pressure level. Most of the experts believe that hypertension is due to a number of different underlying causes and here heredity plays an important role. Apart from heredity, such causes like tension and stress, environment and personality, high salt diet, food habits and a tendency to overweight can be considered as the risk factor behind hypertension. Obesity is often an insidious problem causing many serious diseases. It is on the rise in the most prosperous societies around the world. Obesity has always been a reason to increase the blood pressure level in almost all socioeconomic groups, both in men as well as in women. It starts most commonly in the late 20's or early 30 's. Along with hypertension obesity has always been a reason for several other diseases as diabetes mellitus, high cholesterol, coronary heart disease, strokes and likewise. A well-balanced diet with low-calorie intake and regular exercise can definitely help an individual to overcome obese.

Body mass index (BMI) is the simplest acceptable tool for determining relative body fatness in both clinical and epidemiological studies and was recommended as a universal criterion of overweight and obesity (Prentice and Jebb, 2001; World Health Organization, 2014). Body mass index (BMI) usually defines body fatness as an index of weight relative to height and is generally considered a valid index of adiposity (Gundogdu, 2008). The relationship between BMI and BP has long been the subject of epidemiological research. Obese people suffer an extent of excess weight; they are vulnerable to diabetes, hypertension and coronary heart disease (Clegg and McKean, 1999; Humayun et al. 2009).

\section{Materials and Method:}

The present study proposes to study the effects of altitude in respect of blood pressure measures along with Body Mass Index (BMI) among the Monpas residing in the high elevation of approx 10,000 feet above sea level in the Tawang district of Arunachal Pradesh. Purposive sampling technique has been used and also house to house survey has been done to collect the data.

The Tibetan area of Arunachal Pradesh comprises the Monpa tribes. Monpas are a major tribe of Arunachal Pradesh. Tawang is a centre place for most of the Monpa tribes. Tawang Monpa is one of the subgroups of the Monpa tribe. The Monpa tribe of Arunachal Pradesh lives in different altitude of the State, who follows Buddhist religion and professes Mahayana Buddhism. 


\section{(C) Jyotismrita Phukan, Dr. Tiluttoma Baruah}

For counting blood pressure altogether 524 (267 are males and 257 are females). As the study is made on the adults of Tawang the age group varies from 18-76 years of age in males and 18-70 years of age in the female category. Two anthropometric measurements Height and Weight to measure the Body Mass Index (BMI) as well as Blood Pressure is taken from the participants. Height (in $\mathrm{cm}$.) was measured by anthropometer and weight (in $\mathrm{kg}$.) was measured by the weighing machine. The blood pressure ( $\mathrm{mmHg}$ ) was taken in the morning after breakfast with mercury sphygmomanometer and stethoscope.

\section{Results:}

Table I: Physical attributes of the Participants

\begin{tabular}{|c|c|c|c|c|c|c|}
\hline VARIABLES & \multicolumn{2}{|c|}{ MALE } & \multicolumn{2}{|c|}{ FEMALE } & \multicolumn{2}{|c|}{ TOTAL } \\
\hline \multirow{3}{*}{ GENDER } & $\mathrm{n}$ & $\%$ & $\mathrm{n}$ & $\%$ & & \\
\hline & 267 & 50.95 & 257 & 49.05 & 524 & 100 \\
\hline & mean & S.D & mean & S.D & mean & S.D \\
\hline HEIGHT(CM) & 165.3 & 6.15 & 153.76 & 5.64 & 159.64 & 8.26 \\
\hline WEIGHT(KG) & 68.28 & 11.86 & 60.87 & 11.54 & 64.65 & 12.27 \\
\hline BMI & 24.94 & 3.8 & 25.72 & 4.45 & 25.32 & 4.14 \\
\hline \multicolumn{7}{|c|}{ B.P(mm/hg) } \\
\hline SYSTOLIC & 128.8 & 9.91 & 124.26 & 9.64 & 126.57 & 10.03 \\
\hline DIASTOLIC & 85.09 & 6.8 & 82.98 & 7.34 & 84.05 & 7.14 \\
\hline
\end{tabular}

The Table I represents the mean height, weight and BMI of the participants were $159.64 \pm 8.26 \mathrm{~cm}, 64.65 \pm 12.27 \mathrm{~kg}$ and $25.32 \pm 4.14 \mathrm{~kg} / \mathrm{m} 2$ respectively. With the males having a higher mean height of $(165.3 \pm 6.15 \mathrm{~cm})$ and weight $(68.28 \pm 11.86 \mathrm{~kg})$ than the mean height $(153.76 \pm 5.64 \mathrm{~cm})$ and weight $(60.87 \pm 11.54 \mathrm{~kg})$ of their female counterparts. The mean BMI of the female participants $(25.72 \pm 4.45 \mathrm{~kg} / \mathrm{m} 2)$ was found to be higher than the mean BMI of the male participants $(24.94 \pm 3.8 \mathrm{~kg} / \mathrm{m} 2)$. The result also shows the mean systolic and diastolic blood pressures of the participants to be $126.57 \pm 10.03 \mathrm{mmHg}$ and $84.05 \pm 7.14 \mathrm{mmHg}$ respectively. The mean systolic and diastolic BP was found to be higher in male participants $(128.8 \pm 9.91 \mathrm{mmHg}$ and $85.09 \pm 6.8 \mathrm{mmHg}$ respectively) than their female counterparts $(124.26 \pm 9.64 \mathrm{mmHg}$ and $82.98 \pm 7.34 \mathrm{mmHg}$ respectively). 
The Researchers' - Volume VI, Issue I, 10 March-2020

ISSN : 2455-1503

International Research Journal (Double-blind peer-reviewed)

Impact Factor - 3.635

Date of Acceptance : 12 October 2019

DOI - 10.21276/tr.2020.6.1.AN5

(C) Jyotismrita Phukan, Dr. Tiluttoma Baruah

Table II: BMI distribution among the participants

\begin{tabular}{|c|c|c|c|c|c|c|}
\hline CATEGORY & MALE & $\%$ & FEMALE & $\%$ & TOTAL & $\%$ \\
\hline Underweight & 3 & 1.12 & 8 & 3.11 & 11 & 2.1 \\
\hline Normal Weight & 122 & 45.7 & 113 & 43.97 & 235 & 44.85 \\
\hline Over Weight & 115 & 43.07 & 91 & 35.41 & 206 & 39.31 \\
\hline Obese & 27 & 10.11 & 45 & 17.51 & 72 & 13.74 \\
\hline Total & 267 & 100 & 257 & 100 & 524 & 100 \\
\hline
\end{tabular}

Table II shows the distribution of body weight of both the categories. The table shows that of the total 524 individuals highest number is found in the category of normal weight i.e 235 (44.85\%), followed by overweight 206(39.31\%), obese $72(13.74 \%)$ and least is seen in the category of underweight $11(2.1 \%)$.

\section{Table III Systolic and diastolic blood pressure of female participants in different BMI categories}

\begin{tabular}{|c|c|c|c|c|c|}
\hline \multirow{2}{*}{ BMI category } & \multicolumn{5}{|c|}{ Blood pressure(mm/hg) } \\
\cline { 2 - 6 } & & \multicolumn{2}{|c|}{ systolic } & \multicolumn{2}{c|}{ diastolic } \\
\cline { 2 - 6 } & $\mathrm{N}$ & Mean & S.D & Mean & S.D \\
\hline underweight & 8 & 122.75 & 5.44 & 80.50 & 2.07 \\
\hline normal weight & 113 & 121.26 & 7.69 & 81.58 & 7.13 \\
\hline over weight & 91 & 125.27 & 10.40 & 83.38 & 7.09 \\
\hline obese & 45 & 130.00 & 10.25 & 86.13 & 7.99 \\
\hline total & 257 & 124.82 & 8.45 & 82.90 & 6.07 \\
\hline
\end{tabular}

Minimum mean systolic BP were found in the underweight category $(122.75 \pm 5.44 \mathrm{mmHg})$ and the maximum mean systolic BP were found among the obese $(130.00 \pm 10.25 \mathrm{mmHg})$ category. While minimum mean diastolic BP were found in the underweight category $(80.50 \pm 2.07 \mathrm{mmHg})$ and the maximum mean diastolic BP were found among the obese $(86.13 \pm 7.99 \mathrm{mmHg})$ category. The result though not statistically tested showed that mean systolic and diastolic BP increases with increasing BMI level among the participants. 
The Researchers' - Volume VI, Issue I, 10 March-2020

International Research Journal (Double-blind peer-reviewed)

Date of Acceptance : 12 October 2019

(C) Jyotismrita Phukan, Dr. Tiluttoma Baruah
ISSN : 2455-1503

Impact Factor - 3.635

DOI - 10.21276/tr.2020.6.1.AN5

Table IV: Systolic and diastolic blood pressure of male participants in different BMI categories

\begin{tabular}{|c|c|c|c|c|c|}
\hline \multirow{2}{*}{ BMI category } & \multicolumn{5}{|c|}{ Blood pressure(mm/hg) } \\
\cline { 2 - 6 } & & \multicolumn{2}{|c|}{ systolic } & diastolic \\
\cline { 2 - 6 } & $\mathrm{N}$ & Mean & S.D & Mean & S.D \\
\hline underweight & 3 & 119.33 & 11.37 & 82.67 & 8.33 \\
\hline normal weight & 122 & 126.41 & 8.69 & 83.54 & 6.53 \\
\hline over weight & 115 & 129.84 & 9.68 & 85.67 & 6.36 \\
\hline obese & 27 & 136.22 & 11.57 & 89.85 & 7.42 \\
\hline total & 267 & 127.95 & 1.38 & 85.43 & 0.91 \\
\hline
\end{tabular}

Minimum mean systolic BP were found in the underweight category $(119.33 \pm 11.37 \mathrm{mmHg})$ and the maximum mean systolic BP were found among the obese $(136.22 \pm 11.57 \mathrm{mmHg})$ category. While minimum mean diastolic BP were found in the underweight category $(82.67 \pm 8.33 \mathrm{mmHg})$ and the maximum mean diastolic BP were found among the obese $(89.85 \pm 7.42 \mathrm{mmHg})$ category. The result though not statistically tested showed that mean systolic and diastolic BP increases with increasing BMI level among the participants.

Table V - Correlation between BMI Classification and blood pressure of the population

\begin{tabular}{|l|l|l|}
\hline & SBP & DBP \\
\hline BMI & 0.323728 & 0.267021 \\
\hline
\end{tabular}

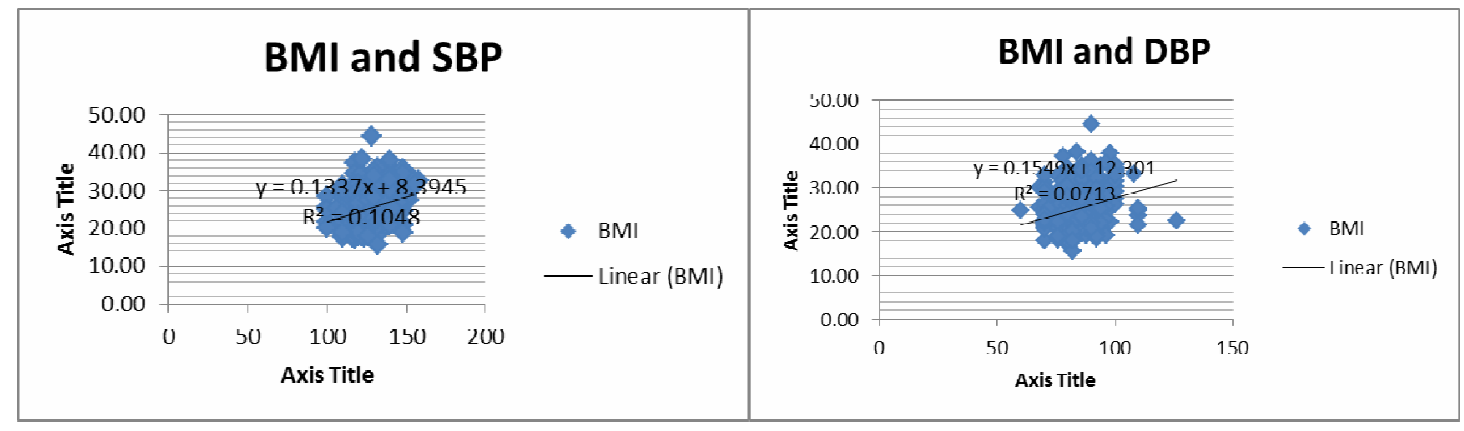




\section{(c) Jyotismrita Phukan, Dr. Tiluttoma Baruah}

\section{Discussion:}

The objective of the study is to see if there is any relation BMI with blood pressure. From the total 524 individuals, maximum participants are found in the normal weight category which makes $44.85 \%$ of the total. The very rare number is seen in the underweight category $2.1 \%$ of the total. The study also reveals that with the increase of age there is a gradual increase in BMI along with Systolic and Diastolic blood pressure among the female participants. While a different scenario is seen among the male participants. The results show a gradual fluctuation of BMI, Systolic and Diastolic blood pressure in accordance with the age. It is also seen that a gradual fluctuation while categorizing BMI category of the females in relation to Systolic blood pressure. While diastolic blood pressure increased in accordance with BMI category. In the male category, it is found that with the increase of BMI category there is an increase in both the Systolic and Diastolic blood pressure.

High prevalence of hypertension and its relationship to obesity points on the importance of early detection and need to implement preventive measures and start education from early life. Physical inactivity, smoking and alcohol consumption in addition to the high prevalence of obesity and overweight are indicators of poor lifestyle and general ignorance. Public health authorities should be more and permanently active.

Acknowledgement: The authors would like to pay regards to Indian Council of Medical Research and to all the participants for their cooperation.

\section{References:}

Bhasin MK and L.P Singh 1992. A Study of Anthropometric Parameters and Lung Functions in Kasmiri Muslim Adults of Jammu and Kashmir, India- A Comparison with the Other Populations Groups of the State. J. Hum. Ecol., 3(3): 221-223.

Biswas, D, N.C Hazarika, D.Hazarika, P.Doloi and J.Mahanta, 2002, Study on nutritional status of Tea garden workers of Assam with special emphasis to Body Mass Index (BMI) and Central Obesity, Human Ecology, volume 13(4): 299-302 
The Researchers' - Volume VI, Issue I, 10 March-2020

International Research Journal (Double-blind peer-reviewed)

Date of Acceptance : 12 October 2019
ISSN : 2455-1503

Impact Factor $\mathbf{-} \mathbf{3 . 6 3 5}$

DOI - 10.21276/tr.2020.6.1.AN5

\section{(C) Jyotismrita Phukan, Dr. Tiluttoma Baruah}

Chakma T, P.K Meshram, P.V Rao, S.B Singh and Kavishwar, 2009. Nutritional status of Baiga- A primitive tribe of Madhya Pradesh, Anthropologist, volume: 11(1)pp 39-43

Clegg, E. J., D. Jeffries and G. A. Harrison. 1976. Determinants of blood pressure at high and low altitudes in Ethiopia. Proceedings of the Royal Society, London B, 194:63-82.

Gupta K. 2008, High Blood Pressure: Causes, Prevention and Treatment, Orient Paperbacks, ISBN 13:978-81-222-0421-6

Goswami, M.C. 1990. The People of Arunachal Pradesh: A Physical Survey. Directorate of Research, Government of Arunachal Pradesh, Itanagar.

Greener Pastures 2014 The Monpa Tribe of Arunachal Pradesh | Celebrating Indigenous Peoples

Gupta, R. and A. Basu. 1981. Variation in body dimensions in relation to altitude among the Sherpas of eastern Himalayas. Annals of Human Biology, 8:145-51. 